\title{
A Tax Register from Roman Fayum
}

\author{
Nikolaos Gonis*
}

\begin{abstract}
Revised edition of an Arsinoite tax register of the second/third century.

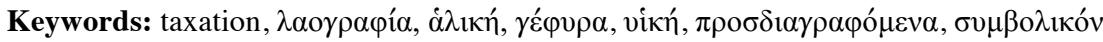

https://doi.org/10.1515/apf-2021-0005
\end{abstract}

The first edition of the papyrus discussed below appeared in a publication whose readership is not primarily papyrological. ${ }^{1}$ It contains much of value, but some problematic readings affect the reconstruction and overall understanding of the text. I present a revised edition, based on the photograph that accompanies the ed.pr.

This is a fragment of an account of payments of capitation taxes from the Arsinoite nome, assigned to the late second or early third century. Six men would have been listed in the original document (1-4, the extant

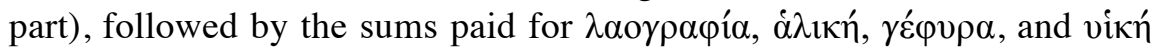
(5-9). After an entry of obscure import (10), there is a total for $\lambda \alpha o \gamma \rho \alpha \varphi$ í $\alpha$ that implies twelve annual payments (11). These taxes appear in the same order in P.Petaus 42 (184-6) and SB XXII $15822\left(3^{\text {rd }}\right.$ c.); cf. also P.Köln II $95\left(2^{\text {nd }} / 3^{\text {rd }}\right.$ c. $)$, which substitutes $\pi \rho \rho \theta \mu \varepsilon i ́ o v$ for $\gamma \varepsilon \varphi v ́ \rho \alpha \varsigma$, and SB XVI $12834\left(2^{\text {nd }} / 3^{\text {rd }} c.\right)$. The rates are the usual ones, with small variations.

The second payment of $\lambda \alpha o \gamma \rho \alpha \varphi$ í $\alpha$ reflects the standard Arsinoite rate of 40 drachmas, with 2 drachmas 3 obols for surcharges ( $\pi \rho \circ \sigma \delta 1 \alpha \gamma \rho \alpha \varphi o^{-}$ $\mu \varepsilon v \alpha)$ and 2 obols 3 chalci for the scribal fee ( $\sigma \nu \mu \beta o \lambda \iota \kappa o ́ v)$, or with $\pi \rho \circ \sigma-$

* Kontakt: Nikolaos Gonis, Department of Greek and Latin, University College London, London WC1E6BT, <n.gonis@ucl.ac.uk>

${ }^{1}$ B. Kiss, 'P. Prag. Gr. III 95b', in E. Juhász (ed.) Byzanz und das Abendland VI. Studia Byzantino-Occidentalia (Budapest 2019) 259-70, with a colour photograph on p. 259. The volume is available on line, at <http://byzantium.eotvos.elte.hu/kiadvanyok/on-line/> (last accessed 8 May 2021). 


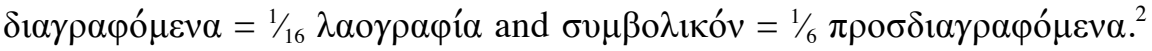
The first payment of $\lambda \alpha o \gamma \rho \alpha \varphi$ í $\alpha$ may suggest a slightly different rate for the two additional charges, as we will see.

The other three taxes are smaller imposts for which no $\sigma u \mu \beta 0 \lambda \iota \kappa o ́ v$ was paid. ${ }^{3}$ The $\dot{\alpha} \lambda \iota \kappa n$ in the Fayum was assessed at 4 obols, with extra charges of 4 chalci $(2+2)$. At this rate, six men would have paid 4 dr. 3 ob.; here we have $4 \mathrm{dr} .+1 \frac{1}{2} \mathrm{ob}$., since only the $\pi \rho \sigma \sigma \delta 1 \alpha \gamma \rho \alpha \varphi$ ó $\mu \varepsilon v \alpha$ were included (see below, $6 \mathrm{n}$.).

The less well-known $\gamma \dot{\varepsilon} \varphi v \rho \alpha$ was assessed at 2 ob. 2 ch. in P.Stras. V $419(134 / 5)$, at $2 \frac{1}{2} \mathrm{ob}$. in SB XVI $12816.68(179)$, and at $2 \frac{1}{2} \mathrm{ob} .+2 \mathrm{ch}$. as surcharge in P.Petaus $42(184-6)$ and SB XVI $12834.12\left(2^{\text {nd }} / 3^{\text {rd }} c.\right)$. The last rate probably underlies the cumulative payment of $2 \mathrm{dr} .4 \mathrm{ob}$. here, with $1 / 2 \mathrm{ob}$. rounded down. ${ }^{4}$

The Arsinoite rate of the vikn was $1 \mathrm{dr}$. $1 \mathrm{ob}$., of which $1 / 2 \mathrm{ob}$. represents surcharges. Our account conforms to this picture.

The combined payments for $\pi \rho 0 \sigma \delta 1 \alpha \gamma \rho \alpha \varphi \mu_{\mu} \varepsilon v \alpha$ and $\sigma v \mu \beta 0 \lambda \iota \kappa o ́ v$ amount to $18 \mathrm{dr}$. $4 \frac{1}{2}$ ob. (1. 9), of which $5 \frac{1}{2} 2$ ob. are $\pi \rho 0 \sigma \delta 1 \alpha \gamma \rho \alpha \varphi$ ó $\mu \varepsilon v \alpha$ on the three smaller taxes (11. 6-8). The extra charges on the $\lambda \alpha$ o only partly extant (1.5); for the account to balance, they should total $17 \mathrm{dr}$. 5 ob., but the expected sum, also suggested by 1.11 , is $17 \mathrm{dr} .3 \mathrm{ob}$. There is a difference of 2 obols, arguably a very small sum; ${ }^{5}$ see further $5 \mathrm{n}$.

The first editor thought that the text was written by the same hand as SB XVI 12834 and perhaps P.Köln II 95 (p. 270). This does not hold for the latter, but there are close affinities with the former, which uses the same abbreviations and symbols. Apart from the writing of $\pi \rho(o \sigma \delta 1 \alpha \gamma \rho \alpha-$ $\varphi$ ó $\mu \varepsilon v \alpha)$ pointed out by the editor, we may note the the abbreviation of

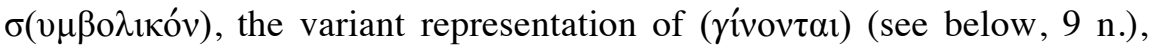
and the addition of a dot under the obol symbol. I am not entirely sure that this is the work of one and the same scribe, but it certainly comes from the same scribal milieu. ${ }^{6}$

\footnotetext{
${ }^{2}$ Cf. J.C. Shelton, 'The Extra Charges on Poll-Tax in Roman Egypt', CE 51 (1976) 178-84, at 182; A. Gara, Prosdiagraphomena e circolazione monetaria (1976) 143, 145. V.B. Schuman, 'The "Rate" of the Prosdiagraphomena', BASP 16 (1979) 125-30, offers a somewhat different view.

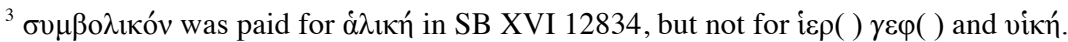

${ }^{4}(2$ ob. 6 ch. $) \times 6=12$ ob. 36 ch. $=4$ dr. 4 ob. 4 ch. $(=1 / 2$ ob. $)$.

${ }^{5}$ It may be a mere coincidence that we obtain 2 obols if we add the unrecorded payment

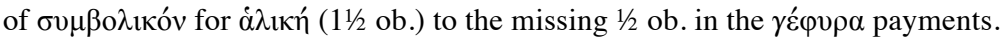

${ }^{6}$ In view of other connections, it would not be surprising that a papyrus formerly in Wessely's private collection is related to one in Vienna (SB XVI $12834=$ SPP XX 49r +
} 
$1 \quad \ldots .\left[\begin{array}{ccc}c .9 & ] . .[\end{array}\right.$

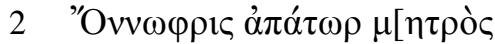

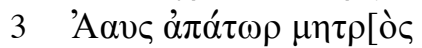

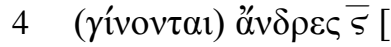

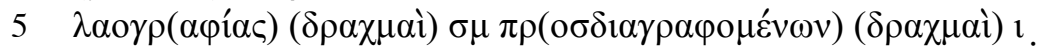
$[\sigma(v \mu \beta о \lambda \imath \kappa о \hat{)})(\delta \rho \alpha \chi \mu$.$) . ( -\omega \beta \beta о \nu o v)]$

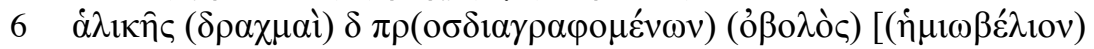

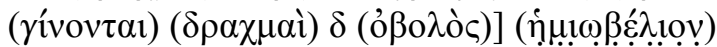

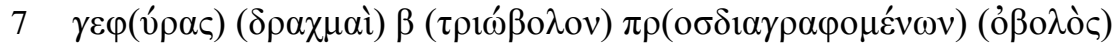
$\left[\left(\gamma^{\prime}(v o v \tau \alpha l)\right](\delta \rho \alpha \chi \mu \alpha i) \beta(\tau \varepsilon \tau \rho \omega ́ \beta o \lambda o v)\right.$

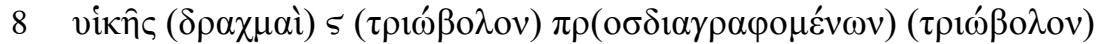

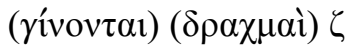

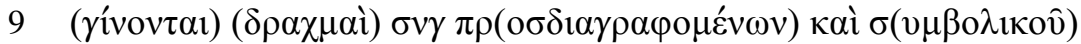

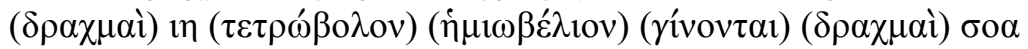

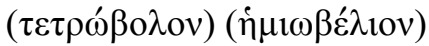

10 ]. $1 \pi() .(\dot{\varepsilon} \tau) \beta$

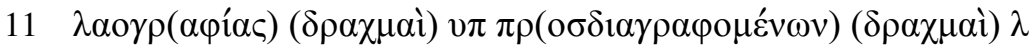

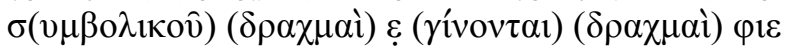

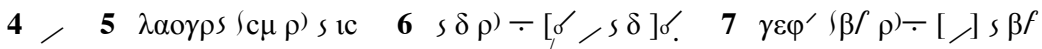

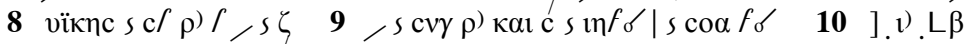

$11 \lambda \alpha 0 \gamma \rho s, v \pi \rho)\{\lambda \mathrm{c} s \varepsilon, s \varphi 1 \varepsilon$
}

(2ff.) Onnophris, fatherless, mother ...

Aaus, fatherless, mother ...

Total 6 men.

Poll-tax 240 dr., surcharges 16(?) dr., receipt fees ... dr. ... ob.

Salt-tax 4 dr., surcharges $1 \frac{1}{2} 2$ ob., total 4 dr. 11/2 ob.

Bridge-tax 2 dr. 3 ob., surcharges 1 ob., total 2 dr. 4 ob.

Pig-tax 6 dr. 3 ob., surcharges 3 ob., total 7 dr.

Total $253 \mathrm{dr}$., surcharges and receipt fees $18 \mathrm{dr}$. 41/2 ob., total $271 \mathrm{dr}$. $4 \frac{1}{2}$ ob.

... 2 years (?)

Poll-tax $480 \mathrm{dr}$., surcharges $30 \mathrm{dr}$., receipt fees $5 \mathrm{dr}$., total $515 \mathrm{dr}$.

62r, earlier PERF 263 and 276), but this may be merely chance: the Vienna papyrus was acquired in the 1880s, while Wessely bought his papyri in 1904 (see P.Prag. I, p. 3). 


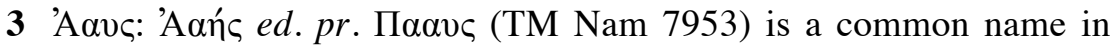
the Fayum, but this form is new.

5 i.[. Ed. pr. read 15 before the lacuna, and left the line unrestored. 15 is indeed the more natural interpretation of the writing, but $1 \varepsilon=15 \mathrm{dr}$. is expected, and receives support from the figures in 1. 11. If the sum paid for $\pi \rho 0 \sigma \delta 1 \alpha \gamma \rho \alpha \varphi$ ó $\mu \varepsilon v \alpha$ was $16 \mathrm{dr}$., we would have to assume that $1 \mathrm{dr} .5$ ob. was paid for $\sigma u \mu \beta 0 \lambda \iota \kappa o ́ v$, to bring the total of extra charges to $17 \mathrm{dr} .5$ ob. (see above, introd.). This would imply a lower rate for $\sigma v \mu \beta 0 \lambda \iota \kappa o ́ v$ than usual ( $1 \mathrm{ob}$. per $1 \mathrm{dr}$. of $\pi \rho 0 \sigma \delta 1 \alpha \gamma \rho \alpha \varphi$ ó $\mu \varepsilon v \alpha$; for 16 dr., it would be 2 dr. 4 ob.). On the other hand, if we read $1 \varepsilon$, these $17 \mathrm{dr} .5 \mathrm{ob}$. could have been split as 15 dr. +2 dr. 5 ob., 15 dr. 1 ob. +2 dr. 4 ob., or 15 dr. 11/2 ob. +2 dr. $3 \frac{1}{2}$ ob.; the totals for $\sigma 0 \mu \beta$ o $\lambda$ iкóv will be high, though admittedly these are very small sums. In view of these uncertainties, I have not restored the text in full.

6 The first editor offered no supplements for the lacuna but noted (p. 267 ) that something was visible above the end of 1.7 . This last trace must be the lower part of the symbol for $\dot{\eta} \mu \omega \beta \varepsilon \dot{\varepsilon} \lambda$ iov. It does not have the right form for the obol sign, which would have been written if $\sigma v \mu \beta 0 \lambda$ เкóv had been paid. There also seems to be no room to restore a payment of $\sigma v \mu \beta 0 \lambda$ iкóv.

$7 \gamma \varepsilon \varphi(v \rho \rho \varsigma): \pi \alpha 1(\delta i ́ \sigma \kappa \omega v) e d$. $p r$. I have resolved the form required by grammar, though only $\gamma \varepsilon \varphi v ́ \rho n \varsigma$ and $\gamma \varepsilon \varphi v \rho \omega \hat{v}$ are attested when the word is written out in full. It is preceded by i $\varepsilon \rho($ ) in SB XVI 12834. This was apparently a 'tax for the maintenance of bridges' (P.Ryl. II $225.51 \mathrm{n}$.); see further P.Heid. X 451.12 n., pp. 406-10.

[( $\gamma^{\prime}$ vov $\left.\left.\tau \alpha \mathrm{l}\right)\right]$. Not restored in ed.pr., but the supplement is obvious.

86 dr. 3 ob. +3 ob. $=7$ dr. Even without this entry, it would have been clear that the taxes were calculated on the basis of the 6-obol drachma.

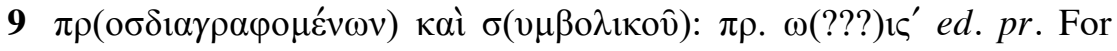
this combination of the two charges, cf. P.Lond. III 1170.7 and 8 (c. 144), SB XVI 12816.75 (179), BGU II 471.10 (186/7), etc. The abbreviation of $\sigma v \mu \beta 0 \lambda$ iкóv here is similar to those in P.Lond. III 1170 and SB XVI 12834 , with a long oblique riser added above sigma. In a different context,

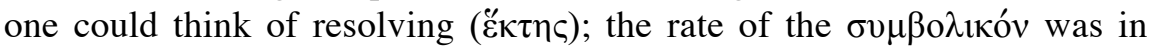
fact $1 / 6$ of the $\pi \rho \sigma \sigma \delta 1 \alpha \gamma \rho \alpha \varphi{ }^{\prime} \mu \varepsilon v \alpha$, but I doubt this was the writer's inten- 


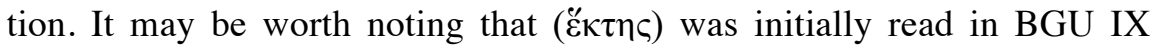
1891.459 , later corrected to $\sigma(v \mu \beta$ o $\lambda$ 1ко $)$ (BL III 25$)$; the abbreviation is slightly different, with a semi-horizontal written over sigma.

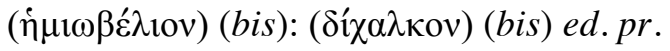

( $\gamma^{\prime}$ vov $\left.\tau \alpha l\right)$ is a long, almost vertical stroke, whereas in 11.8 and 11 a long oblique or semi-horizontal stroke is used. The same variation in the form of this symbol is in evidence in SB XVI 12834.

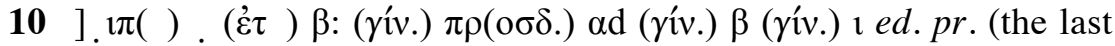
( $\gamma^{\prime}$ v. ) belongs to the line below, and $\mathrm{t}$ is the foot of the ( $\gamma^{\prime}$ vov $\tau \alpha \mathrm{l}$ ) abbreviation from the line above). F. Reiter has offered a tentative though ingenious interpretation of this line, according to which the papyrus may record payments from six men who had paid their taxes separately from the rest of their community, perhaps after their return from anachoresis. "As the payment in 1.11 is not preceded by other names, I suppose it is related to the same group. In this case, the amount might involve two (probably preceding) tax years, for which the obligations have not yet been fulfilled,

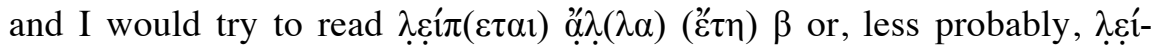
$\pi(\mathrm{ov} \tau \alpha \mathrm{l}) \dot{\alpha} \pi(\mathrm{o})$ (') $\tau \hat{\omega} v) \beta$." The line could have been set out in relation to the lines above and below, as a subtitle.

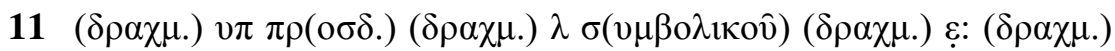
$\mu .(? ? ?) \pi \rho(0 \sigma \delta).(\delta \rho \alpha \chi \mu$.) $\lambda \varsigma(\delta \rho \alpha \chi \mu$.) $\sigma ! l e d . p r$. The reading of $\varepsilon$ is not easy ( 5 would also be acceptable), but the arithmetic makes it appear inescapable. Cf. the problem with $15 / 1 \varepsilon$ in 1.5 . 